\title{
The diagnostic problem of multiple intracranial tumours - case report of a pituitary chromophobe adenoma and cerebellar haemangioblastoma
}

\author{
P. D. MOHR \\ M.B., B.Sc., M.R.C.P. \\ J. M. ANDERSON \\ M.B., M.R.C.P. \\ P. FLETCHER \\ M.B., M.R.C.Path. \\ J. M. JEFFERSON \\ D.M., F.R.C.P.

\begin{abstract}
The Department of Neurology, Queen Elizabeth Hospital, Edgbaston, Birmingham and the Department of Neuropathology, University of Birmingham
\end{abstract}

\begin{abstract}
Summary
The clinical and pathological details of a case in which a pituitary chromophobe adenoma and a cerebellar haemangioblastoma occurred simultaneously are presented and the diagnostic problems discussed. This is a rare combination considering the disparate tissue origin of the two tumours.

\section{Introduction}

The simultaneous occurrence in the same person of two separate brain tumours of different histology is an unusual event although well documented. Two main forms can be recognized. In one-the common variety - a primary intracranial tumour is combined with cerebral metastasis from a distant carcinoma. In the other type, which is much rarer, separate primary brain tumours arise simultaneously and usually cause considerable diagnostic and therapeutic problems. The following case is of the latter type and illustrates some of these difficulties.
\end{abstract}

\section{Case report}

In May 1972 a 62-year-old white male abruptly developed unsteadiness of gait and difficulty in focusing his vision which persisted for the next 5 weeks. Bifrontal headache with nausea, vomiting and increase in unsteadiness appeared 2 days before admission to hospital on 19 June 1972. Apart from mild chronic bronchitis and systemic hypertension of fairly recent onset for which he was receiving methyldopa, he had had no significant previous illness and the family history was negative.

General physical examination showed a mild degree of cardiomegaly, his blood pressure was 170/120 $\mathrm{mmHg}$ and there was grade I hypertensive change in the fundi and the optic discs were flat. Visual acuity was $6 / 6$ in the right and 6/12 in the left with normal

Address for reprints: Dr J. M. Anderson at the Department of Neurology, Queen Elizabeth Hospital, Edgbaston, Birmingham. visual fields on Goldman perimetry. There was horizontal nystagmus with the quick component to the right on right lateral gaze. The pupillary reactions were normal and the other cranial nerves were intact. There was left ulnar neuropathy of long standing and mild pyramidal paresis of the left arm and leg with hyperreflexia and the left plantar was equivocal. There was mild cerebellar ataxia in the right limbs and his gait was unsteady but he did not fall specifically to one side.

Electrocardiography and chest X-ray confirmed cardiomegaly and hypertension. Haematological and biochemical screening tests were normal as was a technetium isotope brain scan. Plain skull X-rays, however, showed a large pituitary fossa with ballooning of the floor and erosion of the posterior clinoids. Pituitary function was judged to be normal by estimation of plasma cortisol and the response to hypoglycaemia.

It was felt at this stage that he had suffered a vascular accident in the region of the brain stem, probably related to his hypertension. It was also thought that he had a pituitary adenoma but in the absence of endocrine or visual complications no active treatment was recommended. His hypertension was treated with methyldopa $250 \mathrm{mg}$ t.d.s., his cerebellar symptoms and headache settled and he was discharged on 7 July 1972. However, over the next 2 months there was a definite decline in his condition. His memory became poor, he developed morning headache, he became progressively more unsteady on his feet and his vision deteriorated. He was readmitted to hospital on 18 September 1972.

On examination he was conscious but drowsy and mildly confused. He had cardiomegaly and his blood pressure was $200 / 110 \mathrm{mmHg}$. Fundoscopy again showed grade I hypertensive change without papilloedema but the left disc was judged to be pale. Visual acuity was reduced to counting fingers on each side though the fields were full to confrontation. 
Pupillary reactions were normal. Nystagmus was now evident on lateral gaze to either side. The other cranial nerves were intact. In the limbs the old left ulnar neuropathy was again evident, there was marked ataxia of the right limbs, and the right plantar was extensor.

Full haematological and biochemical investigations were normal as were thyroid and pituitary function tests. Technetium isotope scan was again normal and plain skull X-rays unchanged. Carotid angiography was attempted but was technically unsatisfactory. A neurosurgical opinion was sought from Mr E. A. Turner. The CSF pressure on ventricular tap was normal. Air ventriculography showed symmetrical dilatation of the lateral and third ventricles with a large suprasellar extension of the pituitary lesion indenting and obliterating the anterior part of the third ventricle. It was also noted that the fourth ventricle was displaced backward and to the left.

The possibility of two separate intracranial lesions was considered but abandoned in favour of a single pituitary lesion, probably malignant, extending backward and downward along the clivus as well as upward into the third ventricle. Right ventriculoatrial shunt was undertaken on 28 September, and right temporal craniotomy on 9 October 1972. A large encapsulated pituitary tumour was encountered presenting between the optic and third and fourth cranial nerves and the carotid artery. It was also presenting posteriorly through the back of the sella and under the petro-clinoid ligament. As much as possible of this was removed by suction and material was sent for histological examination. It was reported by Professor W. Thomas Smith as chromophobe pituitary tumour without evidence of a capsule. The tumour cells showed slight pleomorphism, irregular chromatin pattern and occasional mitotic figures (Fig. 1). He considered the histological appearance that of a borderline pituitary carcinoma.

After the operation the patient regained consciousness but developed right ophthalmoplegia and left hemiparesis; his breathing became irregular and he required tracheostomy. Bronchopneumonia supervened which responded to antibiotics. A course of radiotherapy was given to the pituitary region but to no avail. He deteriorated over the next month and died on 16 November 1972.

Autopsy showed that the immediate cause of death was bilateral confluent bronchopneumonia with terminal aspiration of gastric contents. Cardiomegaly (heart weight $470 \mathrm{~g}$ ) was mainly due to concentric hypertrophy of the left ventricle. Generalized atherosclerosis was present and the origin of the right renal artery was stenosed by a circumferential atheromatous plaque. Macroscopically the kidneys

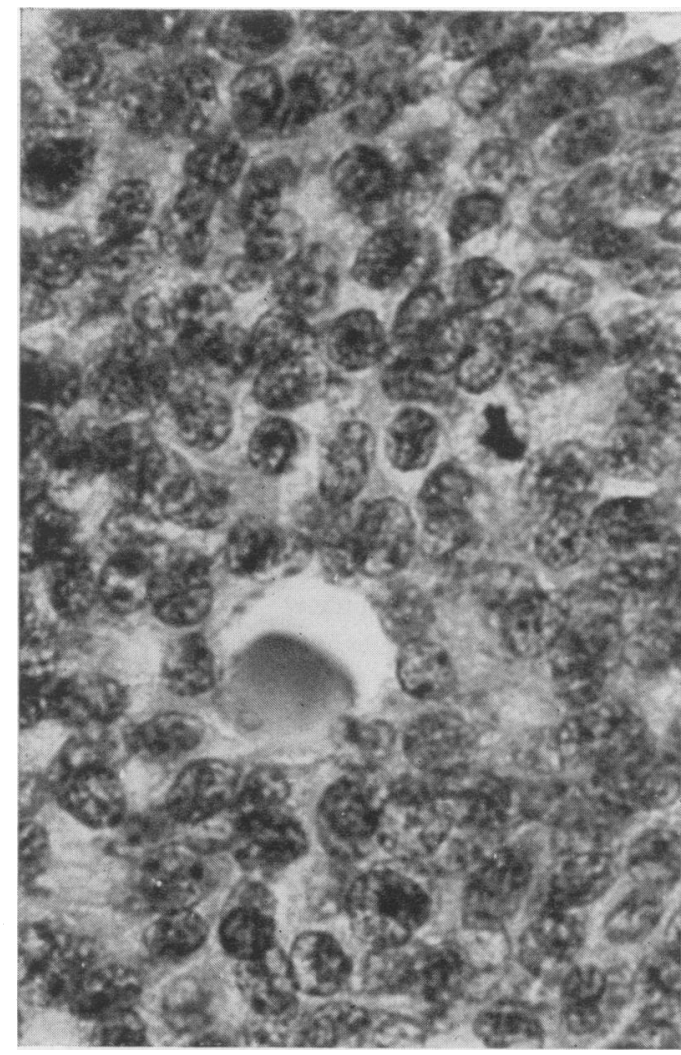

Fig. 1. Biopsy of chromophobe tumour showing slight cellular pleomorphism, irregular chromatin and a mitotic figure. HE $\times 770$.

were normal but histology revealed subcortical scars, probably of vascular origin.

The right ventriculo-atrial shunt was in situ and a right temporal craniotomy had been made. Externally it was evident that the anterior part of the right temporal lobe had been removed. The cerebral arteries showed patches of atheroma. There was no evidence of raised intracranial pressure. The brain was dissected easily from the pituitary tumour but the chiasma and the floor of the third ventricle showed atrophy and gliosis though there was no evidence of direct invasion of these areas by tumour.

Multiple coronal slices of the cerebral hemispheres showed moderate hydrocephalus and the mid-brain and pons were displaced to the left. An old gliotic softening was present on the superior surface of the right cerebellar hemisphere in the territory of the superior cerebellar artery. Parasagittal sections of the cerebellar hemisphere revealed a cyst approximately $3.5 \mathrm{~cm}$ in diameter, displacing the fourth ventricle to the left. In the anterior and inferior aspect of the cyst, bulging into the lumen, was a mural nodule, 


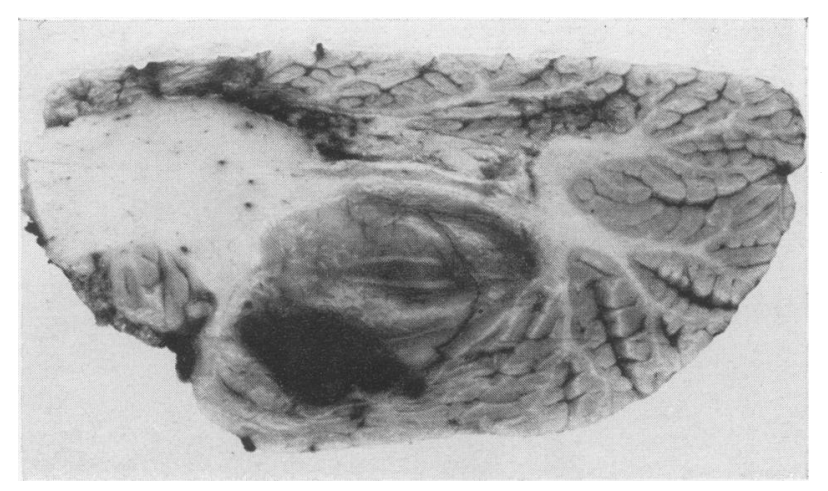

Fig. 2. Parasagittal section of right cerebellar hemisphere with haemangioblastoma cyst and haemorrhagic mural nodule and old gliotic softening on superior aspect of hemisphere. $\times 2$.

$1 \mathrm{~cm}$ in diameter with a smooth even surface (Fig. 2).

Histologically the latter was a typical cerebellar haemangioblastoma consisting of numerous blood spaces and capillaries separated by polygonal and fusiform stromal cells with spheroidal and oval nuclei. Frozen sections demonstrated sudanophilic lipid in the cytoplasm of these cells. In places there was a complex relationship between the tumour and the pia and occasional blood vessels from the tumour appeared to invade adjacent brain (Fig. 3).

The base of the skull was removed intact and decalcified. Part of the pituitary including the posterior extension had been removed surgically and was replaced by muscle. Extensive erosion of the posterior clinoid processes and dorsum sellae had occurred but the dura was intact in these areas. Laterally the tumour had extended into the right cavernous sinus and was displacing the carotid artery upwards and to the right (Fig. 4). Coronal sections of the sella including both cavernous sinuses and a mid-sagittal section of the posterior part of the sella were examined histologically. They confirmed that much of the intrasellar tumour had been removed and was replaced by post-operative granulation tissue. The remaining tumour had similar cytological features to the biopsy. On the right there was infiltration of the cavernous sinus and partial envelopment of the medial aspect of the internal carotid artery. Although the vessel wall was not infiltrated there were tongues of tumour infiltrating connective tissue within the sinus. On the left, a rim of adenohypophysis separated the tumour from the cavernous sinus. The posterior aspect of the floor and the dorsum sellae were eroded by tumour (Fig. 5). The dorsum sellae was represented by two thin trabeculae of lamellar bone and tumour cells were present between trabeculae of reactive bone and were seen merging with the normal bone marrow.

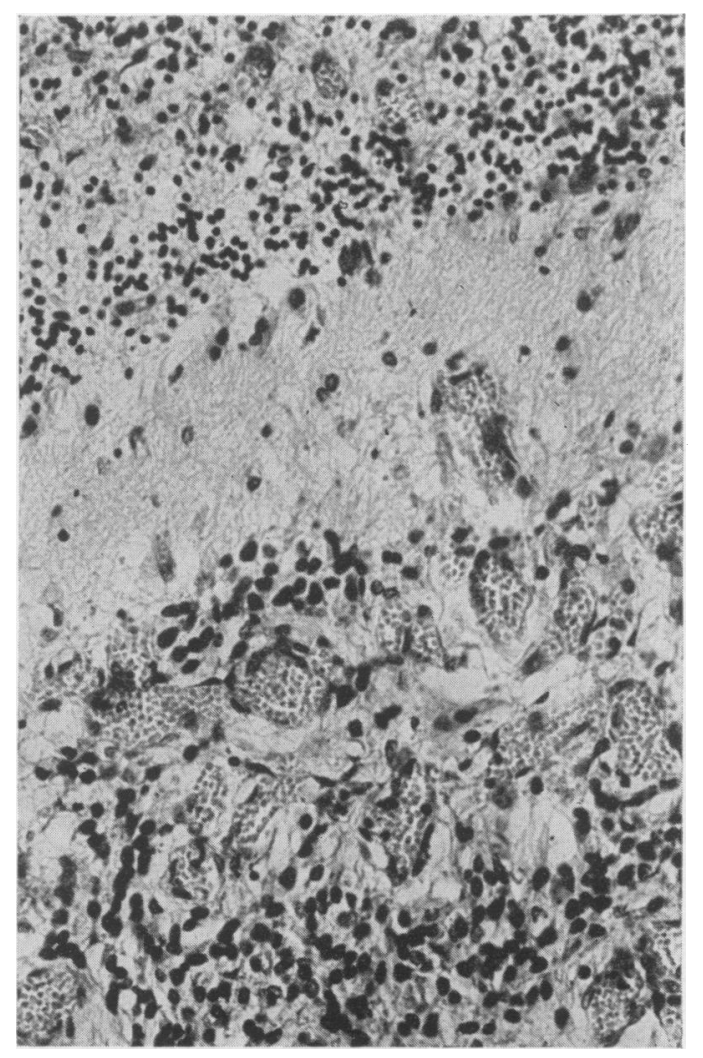

Fig. 3. Cerebellar haemangioblastoma associated with pia of adjacent cerebellar folium. Luxol fast blue, cresyl fast violet. $\times 200$.

\section{Discussion}

Multiple intracranial tumours due to metastases from extracranial carcinoma are commonplace but it only rarely happens that such metastasis occurs by chance together with a primary intracranial tumour. 


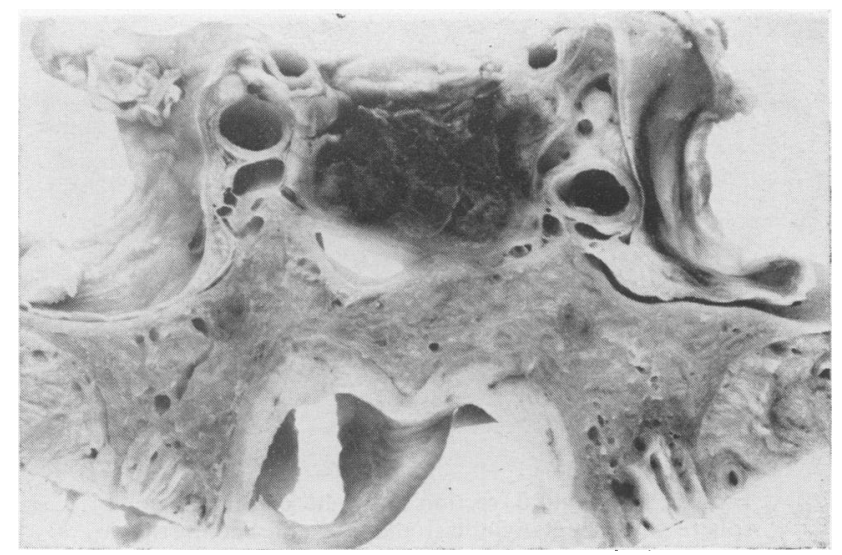

FIG. 4. Coronal section through pituitary fossa showing invasion of cavernous sinus. $\times 2$.

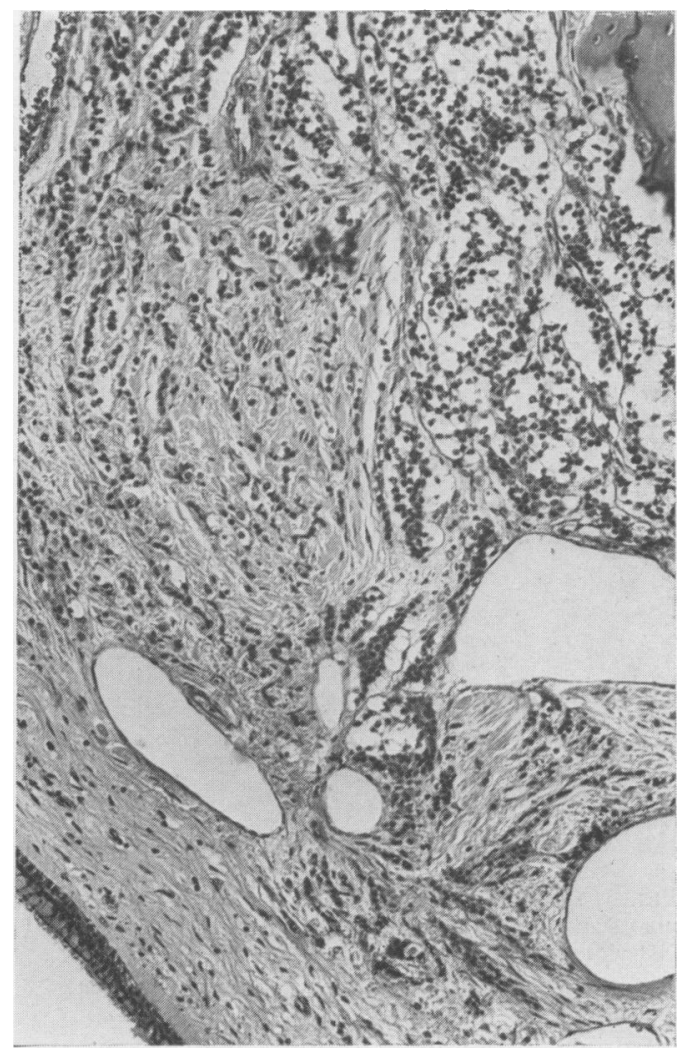

FIG. 5. Pituitary tumour invading sellar floor (top right) and approaching sphenoid air sinus (bottom left). Haematoxylin and eosin. $\times 124$.
Multiple primary intracranial tumours of identical histology, usually gliomas, are still less common, and it has long been debated whether they represent truly separate tumours or are 'multicentric' expression of the same glioma. The subject has been reviewed by Batzdorf and Malamud (1963), Courville (1936) and Roger and Crémeux (1929). Also rare is the combination of a glial tumour with some other type of intracranial tumour (most commonly a meningioma), a topic which has been discussed by Arieti (1944) and Cooper (1969).

We have been unable to find a previous detailed report of a chromophobe pituitary adenoma occurring with a cerebellar haemangioblastoma although Wise, Malamud and Boldrey (1953) quote Dr Louise Eisenhardt as saying that in Cushing's series of 2023 intracranial tumours, of the $\mathbf{3 6 0}$ pituitary tumours one had a cerebellar haemangioblastoma in addition to a chromophobe adenoma. Wise et al. (1955), reporting 172 cases of chromophobe adenoma, do mention one with an 'asymptomatic' chromophobe adenoma who died of the effects of a cerebellar haemangioblastoma.

All authors stress the diagnostic problems that arise with multiple intracranial tumours. That the present case had cerebellar signs was recognized from the start but these were initially believed to be due to a brain stem vascular accident and indeed at autopsy such a lesion was found. It is just conceivable that this infarct was the result of compression of the superior cerebellar artery on the right side by posterior extension of the pituitary adenoma through the dorsum sellae and under the petro-clinoid 
ligament. The displacement of the fourth ventricle and aqueduct seen on ventriculography was thought most likely to be caused by extension of the pituitary adenoma into the posterior fossa. That such extension can occur is recognized. Geoffrey Jefferson (1955) cited four cases of invasive pituitary adenoma where this had happened but each of these had cranial nerve palsies and there were no cerebellar signs. Wolf in the discussion of the paper by Feiring, Davidoff and Zimmerman (1953) tells of a case in which a pituitary tumour 'spread along the brain stem and then grew far beyond its size in the cerebello-pontine angle and capped the original pituitary syndrome with the cerebellar syndrome ... . In the same paper, Smoler (1909) is quoted as describing a pituitary carcinoma with metastasis to the cerebellum. Ogilvy and Jakubowski (1973) report a case of pituitary adenoma with extension to the right cerebello-pontine angle and displacement of the brain stem. The pituitary tumour in our case had certainly extended beyond the pituitary fossa posteriorly and laterally as confirmed at necropsy but it is clear that these extensions were not large enough to cause cerebellar signs which must have been due to the haemangioblastoma. It may be added that the remarkable invasiveness of pituitary adenomas with relatively little cytological evidence of malignancy commented on by Geoffrey Jefferson (1955), Martins; Haues and Kempe (1965) and Ogilvy and Jakubowski (1973) is well illustrated by our case.

We feel that the simultaneous occurrence of these tumours in one person is fortuitous since their origins are entirely different. That chromophobe adenomas arise from the adenohypophysis is not questioned. Some appear to arise spontaneously and some by dedifferentiation of acidophil adenomas (Russell and Rubinstein, 1971). The nature of cerebellar haemangioblastoma is not proved beyond doubt. Russell and Rubinstein (1971) disagree with the suggestion of Casteigne et al. (1968) that the stromal cells are of reticulo-endothelial origin and are inclined to accept a pial and vascular origin for such tumours. Considerable pial attachment was demonstrated in our own case which is acknowledged to be a conspicuous feature of cerebellar haemangioblastomas (Russell, 1950).

\section{References}

ARIETI, S. (1944) Multiple meningioma and meningioma associated with other brain tumors. Journal of Neuropathology and Experimental Neurology, 3, 255.

BatzdoRf, U. \& Malamud, N. (1963) The problem of multicentric gliomas. Journal of Neurosurgery, 20, 122.

Casteigne, P., David, M., Pertuiset, B. \& Escourelle, R. (1968) L'ultrastructure des hémangioblastomes du système nerveux central. Revue Neurologique (Paris), 118, 5.

COOPER, D.R. (1969) Contiguous meningioma and astrocytoma in brain. New York State Journal of Medicine, 69, 969.

Courville, C.B. (1936) Multiple primary tumors of the brain. American Journal of Cancer, 26, 703.

Feiring, E.H., Davidoff, L.M. \& Zimmerman, H.M. (1953) Primary carcinoma of the pituitary. Journal of Neuropathology and Experimental Neurology, 12, 205.

JefFerson, G. (1955) The Invasive Adenomas of the Anterior Pituitary. Sherrington Lecture No. 3. University Press, Liverpool.

Martins, A.N., Haues, G.J. \& Kempe, L.G. (1965) Invasive pituitary adenomas. Journal of Neurosurgery, 22, 268.

OGILVY, K.M. \& JAKUBOWSKI, J. (1973) Intracranial dissemination of pituitary adenomas. Journal of Neurology, Neurosurgery and Psychiatry, 36, 199.

Roger, H. \& Crémeux, Albert (1929) Les tumeurs cérébrales multiples. Annales de Médecine (Paris), 26, 5.

Russell, D.S. (1950) Meningeal tumours. A review. Journal of Clinical Pathology, 3, 191.

Russell, D.S. \& Rubinstein, L.J. (1971) Pathology of Tumours of the Nervous System, 3rd edn. Edward Arnold, London.

SmOler, F. (1909) Zur Operation der Hypophysentumoren auf nasalem Wege. Wiener klinische Wochenschrift, 22, 1488.

Wise, B.L., Malamud, N. \& Boldrey, E.B. (1953) Multiple intracranial tumours: glioma associated with hypophyseal chromophobe adenoma. Journal of Neuropathology and Experimental Neurology, 12, 224.

Wise, B.L., Brown, H.A., Naffziger, H.C. \& Boldrey, E.B. (1955) Pituitary adenomas, carcinomas and craniopharyngiomas. Surgery, Gynaecology and Obstetrics, 101, 185. 